\section{EPHP 2016: Bringing evidence into public health policy: enhancing equity and engendering intersectoral action for health}

\author{
Upendra Bhojani, ${ }^{1}$ Werner Soors ${ }^{2}$
}

Since 2010, the national conferences on bringing Evidence into Public Health Policy (EPHP) serve as a unique platform to promote exchanges among researchers, practitioners and policymakers for better population health in India. With the central objective of contributing to informed policy and action, each EPHP focuses on concepts and initiatives of significant importance for health in India where informed policymaking can make a difference.

The first EPHP in 2010 focused on 'Five years of National Rural Health Mission'. ${ }^{1}$ The National Rural Health Missionnow National Health Mission taking into its ambit the National Urban Health Mission-was and remains a significant structural reform in the Indian health landscape. Paving the road for improved healthcare delivery, the mission connected the health system again with the community by introducing Accredited Social Health Activists, community monitoring and village and district health plans. EPHP 2010 analysed the mission, took stock of the progress made and deliberated on lessons for course corrections.

The second EPHP in 2012 focused on 'Strengthening Health Systems to achieve Universal Health Coverage'. ${ }^{2}$ The concept of Universal Health Coverage fetched political attention in India and renewed the discourse on how to achieve health for all. EPHP 2012 deliberated on this visionary concept and explored the need for systems thinking in health.

Today, in the era of transition from Millennium to Sustainable Development Goals, informed planning is needed more than ever. While the country has made significant progress in improving population health over the last decade, the achievements of Millennium Development Goals (MDGs) remain a mixed bag. We came close to achieving the health targets of reducing child mortality and halting the spread of HIV/AIDS and malaria. However, we are far short of achieving those on reducing maternal mortality. ${ }^{3}$ Most importantly, our overall progress masks raging disparities. Take, for example, our national infant mortality rate, which came down to 40 deaths per 1000 live births: behind this average hide both a comforting 12/1000 in Kerala and an unacceptable 54/1000 in Madhya Pradesh and Assam. ${ }^{3}$ A majority of health outcomes show such wide disparities between states, communities and, ultimately, people. In parallel, the lack of progress in non-health MDGs should be an eyeopener: in 2011, about $59.2 \%$ of the population lived on below two international dollars a day; in 2012, 43.4\% of Indian households lacked basic sanitation facilities and nearly half of India's children were underweight. ${ }^{3}{ }^{4}$ We can no longer close our eyes for the social determinants of health, and of health inequities. Indeed, health cannot be separated from overall wellbeing. If we want to bring health closer to our people, to all of them according to their needs, the policy will have to embrace intersectoral action.

Guided by the spirit of the Sustainable Development Goals that desirably situate health in the broader context that it rightly deserves, the third edition of EPHP focuses on 'Equitable India: All for Health and Wellbeing'. With our continued commitment for open and shared knowledge, this supplement provides the 57 abstracts selected for presentation at EPHP 2016. They cover the thematic areas of 'Equity in maternal health care', 'Food, nutrition \& health', 'Migration, poverty \& health of urban populations', 'Fostering community engagement in health services', Analysing local actors \& processes', 'Insurance \& equitable financial protection for health', 'Role of healthcare expenses in equitable health care', 'Towards equitable healthcare provision', 'From research to better policy \& practice', 'Policy $\&$ health equity', 'Researching health inequities' and 'Health systems \& training initiatives'. Together, they make a case for enhancing equity and engendering intersectoral action for health. In good EPHP tradition, they will lead to informed panel discussions and policy dialogue.

\section{Author affiliations}

${ }^{1}$ Institute of Public Health, Bangalore, Karnataka, India

${ }^{2}$ Institute of Tropical Medicine, Antwerp, Belgium

\section{REFERENCES}

1 Bhojani U, Prashanth NS, Venkataraman V, et al., eds. Bringing Evidence into Public health policy (EPHP) 2010: five years of national rural health mission. BMC Proc 2012;6(Suppl 1). http://www.biomedcentral.com/bmcproc/supplements/6/S1/all (accessed 30 May 2016).

2 Bhojani U, Mishra A, Prashanth NS, et al., eds. Bringing Evidence into Public Health Policy (EPHP) 2012: Strengthening health systems to achieve universal health coverage. BMC Proc 2012;6(Suppl 5). http://bmcproc.biomedcentral.com/articles/ supplements/volume-6-supplement-5 (accessed 30 May 2016).

3 Government of India. Millennium Development Goals_India Country Report 2015. Social Statistics Division, Ministry of Statistics and Programme Implementation, Government of India, 2015. http://mospi.nic.in/Mospi_New/upload/mdg_26feb15.pdf (accessed 30 May 2016).

4 World Bank Group. Data: Poverty headcount ratio at $\$ 1.25$ a day (PPP) (\% of population). http://data.worldbank.org/indicator/SI.POV.2DAY/countries (accessed 30 May 2016). 